Sonic Scope: New Approaches to Audiovisual Culture • Issue Three

\title{
The Trilobite, Or The Fall of Mr Williams: Opera With Integrated Sound
}

Elfyn Jones

Published on: Oct 27, 2021

License: Creative Commons Attribution 4.0 International License(CC-BY 4.0). 


\section{ABSTRACT}

Elfyn Jones, Goldsmiths, University of London

The Trilobite, Or The Fall Of Mr Williams is an opera with integrated sound design, premièred live at Tête à Tête: The Opera Festival on $17^{\text {th }}$ September 2020, and online on $19^{\text {th }}$ September 2020. It forms the final part of a triptych of operas which constitute a PhD project integrating diegetic and meta-diegetic sound into opera composition at Goldsmiths, University of London. In this article, I describe the process of creating the piece and adapting the rehearsal process and parameters of performance under Covid conditions. I situate The Trilobite within a field of converging music and sound practice, particularly in opera, film and theatre, and explain how music, sound, action, text and narrative intertwine in this piece.

This commentary accompanies a video recording of the live première at The Cockpit on the $17^{\text {th }}$ September 2020 and, as such, inevitably displays the limitations of video recordings of work intended for a live audience, however well-made. In particular, some details of the audio described in the commentary may be difficult to hear in this recording, but I hope that it is still possible to discern my overall intent, and to enjoy the presentation on its own merits. Please listen with good quality headphones or speakers to minimise loss of audio definition.

Note from the author:

This article is dedicated to my PhD supervisor Jeremy Peyton Jones, who sadly passed away in July 2021. I would also like to acknowledge the contribution of Michael Hirsch, composer, and Richard Hoecker, swordsmith, who also passed away during the course of this project. Thanks to Dr Lauren Redhead, Goldsmiths, for your continuing support. 


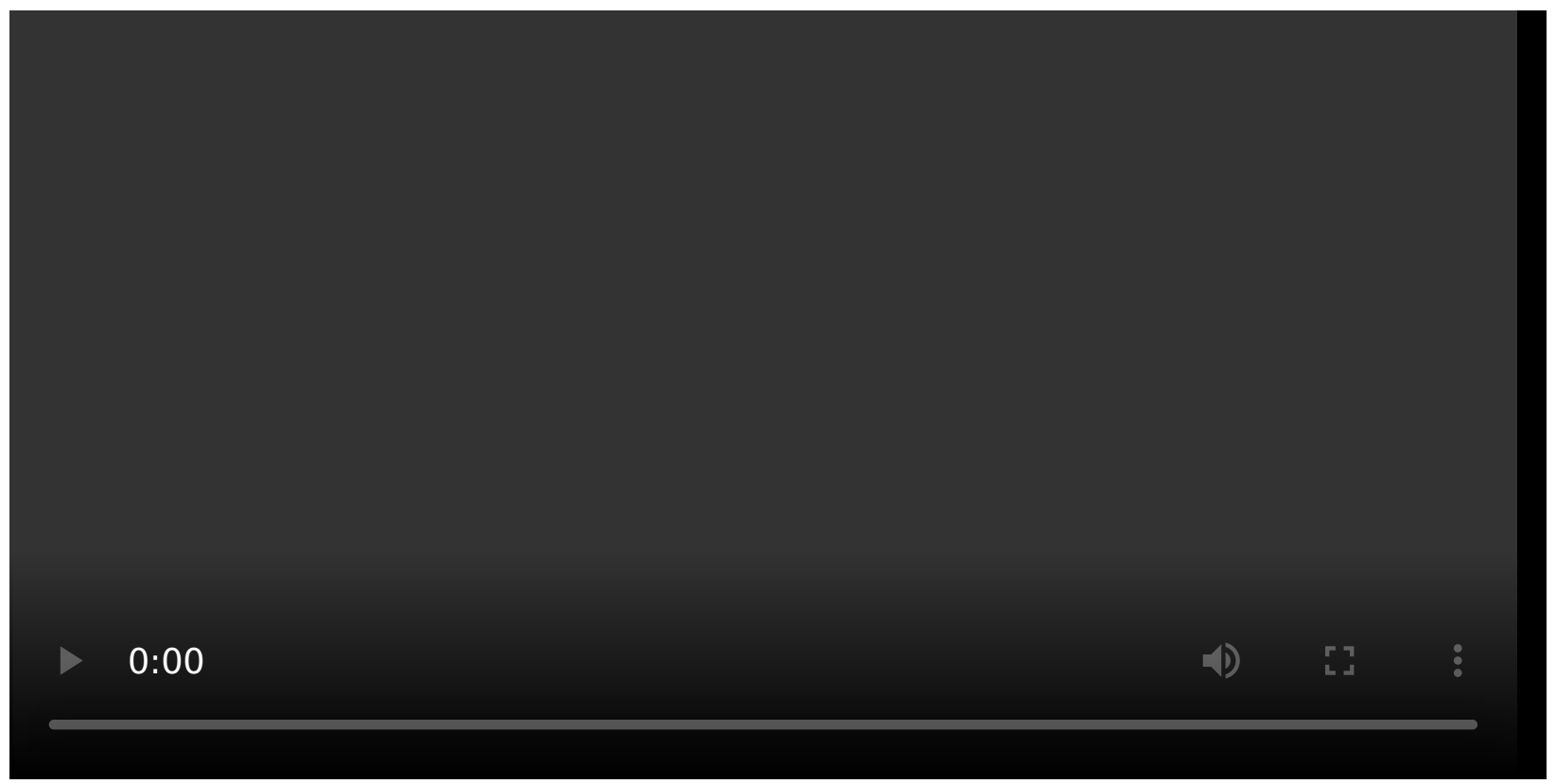

Note: this piece was originally performed at the Téte à Téte Festival in September 2020. For more information about this performance, including a Q\&A with the composer and the festival's Artistic Director, Bill Bankes-Jones, visit: https://www.tete-a-tete.org.uk/event/the-trilobite-or-the-fall-of-mr-williams/.

\section{Introduction}

The Trilobite, Or The Fall Of Mr Williams is a chamber opera in which falling is a visceral metaphor for personal catastrophe. It relates to phases in my own life where I have felt myself stepping into my own personal abyss - only to be saved by a fortuitous upturn in events or a guardian angel. For Glyn Williams there is no such luck.

Glyn is bullied by colleagues and senior management at the secondary school in Devon where he teaches geography. He has failed in his quest for love and undergoes daily humiliation at the hands of the love of his life, the French teacher, and her new husband the gym teacher whose only topic of conversation, and whole raison d' etre, is the $10 \mathrm{k}$ run. The scientific community has failed to recognise the importance (as he sees it) of his discovery of a trilobite in the North Devon fossil beds that proves an ancient connection to North America. And when he finally gets permission to take his rowdy sixth 
formers on a field trip to the Exmoor coast, he finds himself falling off Great Hangman, England' s highest sea cliff, eyeball to eyeball with two angels who, far from saving his life, are intent on crushing his soul.

This piece is the third in a triptych composed for a $\mathrm{PhD}$ project at Goldsmiths in which I explore a practical approach to the integration of diegetic and meta-diegetic sound into opera composition. My theoretical models derive from ideas on intermedial practice presented by Nicholas Cook, Michel Chion and others, and take inspiration from examples of convergent music and sound practice in opera, theatre and film. My work also draws upon the landscapes and soundscapes of Devon where I live. The Trilobite marks a maturation of style, although by no means an endpoint, in the development of my sound practice, and recent events have further influenced the future creative direction of my work.

While The Trilobite was in preparation for its première at Tête à Tête: The Opera Festival last year, Covid-19 struck. This had a profound effect on what could be presented live on stage, and on the rehearsal process itself. The original piece was scored for three singers, three instrumentalists and recorded sound; however, the venue, The Cockpit Theatre in London, could only accommodate one performer on stage under Covid restrictions. The live instrumental music therefore joined the recorded sound as a series of sound cues, and two of the three singers were pre-videoed individually using green screen before being edited to form a series of video cues. The result is a one-man show in which recorded video, audio and live voice engage in a dynamic and transactional relationship, and which delineates (perhaps even more clearly than the original concept) the different levels of narrative through the resulting separation of media.

My $\mathrm{PhD}$ originated as a response to the limitations of presenting contemporary opera on a small scale, particularly the limitations of sonority that result from stripping away the orchestra and chorus out of economic necessity. On the large scale, the operatic ensemble, both vocal and instrumental, contribute hugely to the mise en scène' s energy, style, and emotional subtext, guiding the audience' s journey through the narrative. On a small scale, sound design provides an ideal alternative, anchoring the stage action in an environment that veers between the realistic and the fantastical. In particular, I explore the interaction between music and the sound world of the characters' environment (diegetic sound) and their memories, dreams and hallucinations (meta-diegetic sound). Most of the inspiration and theoretical foundation for my work is drawn from theatre and film, a result partly of the blossoming of sound 
practice in those fields during the last two decades, and partly of a lack of attention given to creative sound design in opera by academics to date.

\section{Music's Changing Relationship with Sound}

Nicholas Cook sees all musical endeavour (and therefore by implication all artistic endeavour) as intermedial: in opposition to a popular conception of music as an autonomous artistic medium, he enquires “can we seriously speak of 'music alone,' when it ceases to be alone the instant we speak of it?" 1 He claims that musical meaning is "the product of an interaction between sound structure and the circumstances of its reception." 2 In multimedia contexts especially, where music is one of several elements in a composite whole, "the broad expressive potential of musical sounds acquires specific meaning by virtue of its alignment with words and pictures - through its transfer, in other words, to a variety of diverse objects." $\underline{3}$ Music is engaged in a 'counterpoint' with other media, through conformance, contest, or complementation, and between denotation and connotation; other elements "mediate the transfer of music into meaning, into communication, into discourse." 4 He argues that different media have "independent dimensions of variance," and that the aesthetic effect of multimedia results from the interaction between them. $\underline{5}$

Theo Van Leeuwen comments on the weakening distinctions between speech, music and other sound as recording technology has increasingly brought music into our daily lives:

The dividing line between speech, music and other sounds is thin. Many of the same kinds of things can be done verbally, musically, or by means of 'noises' ... And if we can use sound to actually do things, to hail or warn or soothe, we can also use it to represent these things, to represent hailing or warning or soothing. $\underline{6}$

His association of sound with actions rather than objects is significant: it underlines the dynamic nature of all sound (music included), both in its nature as a disturbance propagated through an elastic medium, and in its origin in, and therefore association with, activities that produce that disturbance. Furthermore, representation here can mean both denotation (for instance a baby' s crying) and connotation (the emotions of the 
baby and of those who hear it crying), and underlines the rich potential for signification in both musical and non-musical sound.

According to Makis Solomos, we are in the midst of a "change of paradigm ... from a musical culture centred on the note to a culture of sound." $\underline{z}$ There is a new emphasis, he suggests, on the materiality of sound: "The history of musical modernity could be written as the succession of increasingly closer revolutions of materials, going from the emancipation of dissonance up to granular synthesis." $\underline{8}$ He claims that the 'refocussing' on the material at the expense of language and form is the 'primary characteristic' of modernity in music, leading, in the music of Cage, for example, to the disappearance of language and form. $\underline{-}$ With other composers the situation is more complex: "refocussing ... on material and its proliferation [does] not mean that language or form disappear but that one has more and more trouble distinguishing them from the level of material.” $\underline{10}$ Composers from Debussy and Messiaen through Webern to Boulez, Feldman and Arvo Pärt create what Solomos terms "composed resonances," a "pulverisation of time and material to glorify the present and 'sound' ." $\underline{11}$ For Solomos, this model of composed resonance leads to a conception of electroacoustic music as "composed sound" in which form and material become fused, leading to the primacy of studio practice in popular and contemporary art music, and the integration of studio and live practice in the work of modernist composers from Boulez onwards. $\underline{12}$

\section{Sound in Theatre: Musicalisation}

Petra Meyer has identified an "acoustic turn" in theatre. $\underline{13}$ This is one of several 'turns' that have been claimed for theatre practice in recent decades, and heralds "a new attentiveness to the auditory level of theatre" that gave rise to "a new dominance of dance and music" in theatrical performance, as well as "media-technological developments and the new staging possibilities they present today." 14 By abandoning what she calls "psychological-realistic" theatre design, the audible is able to assert equal status in relation to the visible: "the acoustic level creates space itself, gives it dimensions, and determines its atmosphere." 15 She links this experience with the phenomenology of Maurice Merleau-Ponty who deals with "the interplay of imagination 
and the experience of real living space, thus ensuring the relevance of the world as a milieu of perception and thought." $\underline{16}$ For Meyer, the theatrical experience of immersion in such performance spaces mirrors our lived experience.

Music has become an "independent structure of theatre," according to Eleni Varopoulou, who claims that beyond the evident role of music in theatre, we can think of "theatre as music." 17 Hans-Thies Lehmann observes that this 'musicalization' of theatre practice has given rise to "an independent auditory semiotics" of theatre. 18 Through new technology we can "manipulate and structure the entire sonic space of a theatre in a targeted fashion," so that "just like the progression of actions, the musical level is no longer constructed in a linear fashion but rather ... through simultaneous superimposition of sonic worlds." 19 Ross Brown has advocated a "dramaturgy of sound," and Peter Sellars "a total program of sound that speaks to theatre as ontology," both seeking to make theatre sound an integral part of the creative process. $\underline{20}$ They observe a greater emphasis on the auditory sphere in theatrical performance and, along with other practitioners in the field, imply a deepening relationship between sound and music in contemporary theatre practice.

Matthias Rebstock and David Roesner use the term "Composed Theatre" for the work of a number of practitioners who "approach the theatrical stage and its means of expression as musical material." $\underline{21}$ For composer Michael Hirsch, "the reservoir of all art forms is open to a composer." 22 Hirsch uses musique concrète extensively in his work and remarks on an "iridescence between recognition and non-recognition between the quasi-semantic contents of a sound and its abstract-acoustic appearance." 23 Heiner Goebbels brings all elements - music, text, staging, lighting, sound - together from the start: "anything that comes late in the process does not have the power to change anything else." $\underline{24}$ He seeks to "compose like a director [and] direct like a composer" : he values "the rhythm of scenes, the harmonic or contrapuntal relationship of the theatrical elements and ... the melody of a spoken text." $\underline{25}$

\section{Sound and Music in Film: Convergence}

In Audio-Vision: Sound on Screen, Michel Chion lists three modes of listening which lead to different modes of interpreting sound in film. "Causal" listening is used when 
searching for the sources of sounds, and this mode is "constantly manipulated by the audiovisual contract." $\underline{26}$ This often occurs through the phenomenon of what he calls "synchresis," which he defines as "the forging of an immediate and necessary relationship between something one sees and something one hears." 27 Through "codal" listening we understand the meanings of spoken words and other codes. Finally, "reduced" listening "focuses on the traits of the sound independent of its cause and of its meaning" : we are engaging in a form of reduced listening when we identify musical pitch or rhythm in a sound. $\underline{28}$

Reduced listening allows us to exploit what Chion terms "pivot-dimensions" of sound, properties such as pitch, rhythm and register shared by different kinds of sound. He asserts that "sound more than image has the ability to saturate and short-circuit perception," and to "become an insidious means of affective and semantic manipulation." $\underline{29}$ He gives the term "acousmêtre" to an all-seeing, all-knowing and allpowerful character in film who exists only in sound (often as voiceover), and in some cases also has the "gift of ubiquity." $\underline{30}$ An acousmêtre can have magical abilities: "the mere enunciation of a word or sentence can mobilise images or entire scenes," causing things to appear "not only in the mind but right before our eyes and ears." $\underline{31}$

At the School of Sound symposium in April 2015, I found striking examples of sound' s ability to manipulate audiences' emotions in presentations by sound designers Kristian Selin Eidnes Andersen and Nicolas Becker. Their work "moves beyond the traditional realm of feature film sound to look at the landscape between sound effects and music." 32 Andersen' s presentation explained his subtle use of diegetic and metadiegetic sound, such as rainfall or remembered voices, to convey emotional and psychological states of characters on screen in his collaborations with director Lars von Trier. Becker demonstrated his use of sound to underscore the incipient love between the young Cathy and Heathcliff in Wuthering Heights (Andrea Arnold, 2011), as they ride a horse together across Haworth Moor. In a scene without dialogue or music, Becker creates a tender sensuousness from location recordings of breezes through the moorland grass and close-up recording of the actors' breathing, the plod of the horse' s hooves, and the jingling of its harness. Here, sound design occupies space in the soundtrack traditionally occupied by music.

Danijela Kulezic-Wilson argues that "undermining the narrative sovereignty of the spoken word and endorsing the interchangeability of speech and music" in contemporary film-making "promotes modes of perception which can change our expectations of narrative film and emphasize its musical and sensuous 
qualities." 33 Martine Huvenne speaks of an "intertwining" of music and sound, arguing that "it is in the listening" that the sound is perceived either as "pure music ... [or] part of the sonic environment." $\underline{34}$ Conversely, Sergi Casanelles observes that "procedures derived from the practice of sound mixing have become part of the creative process of scoring," enabling composers to "transcend the limitations of the physical world" through a process which he calls "hyperorchestration," augmenting the acoustic orchestra by electronic means. $\frac{35}{}$ Hyperorchestration, he argues, has "narrowed the distance between what we call music and what we call sound design in film ... [and] opens the door to a process of music making for audiovisual media that is highly and naturally integrated with the rest of the sounds present in the soundtrack." $\underline{36}$

\section{Sound Design in Opera: Models and Inspirations}

Traditionally, opera has been resistant to sound enhancement, although it has been employed for outdoor performance, live video streaming, or to solve otherwise intractable acoustical problems. Sound design has however been embraced by several contemporary opera composers including Harrison Birtwistle (The Mask of Orpheus, 1986), Louis Andriessen (Writing to Vermeer, 1999) and John Adams (Dr Atomic, 2007) - although in each of these cases, the sound designer is seen very much as an assistant to the maestro, providing soundscapes interpolated between sections of the composer' s score. Notwithstanding the convergence between music and sound practice in theatre and film composition, the dominant paradigm in contemporary opera composition remains the production of a notated score, except for operas such as Olga Neuwirth's Lost Highway (2003) and Jonathan Harvey's Wagner Dream (2013) where instrumental timbres are augmented by sound processing and synthesis.

Wakonda’ s Dream (2007), composed by Anthony Davis with a libretto by Yusef Komunyakaa, goes further than most in its use of soundscape, with the sound design element being incorporated into the score, and performed on a synthesiser in the orchestra. The Native American lead character is haunted by what he calls the White Man's Coyote, which is only apparent to him and manifests itself in sound. According to the composer, "the goal was to create a kind of magic realism that is both electronic and natural, music and sound." 37 Wakonda’ s Dream was premièred in March 2007 by Opera Omaha at Orpheum Theater, Omaha, with sound design by Earl Howard, who 
comments: "In this opera, I felt there was a real attempt to make it organic... I' $\mathrm{m}$ hoping that opera starts to really take advantage of electronic music and ambient sound in more practical and creative ways." $\underline{38}$

The two pieces, however, that have provided the clearest way forward for my project are not operas but works of theatre. Ross Brown' s sound design for Judith Thompson' s play I Am Yours (score and sound design by Ross Brown for Shared Experience / Royal Court production, London, Ambassadors Theatre, 1998) expresses the strangeness of the internal worlds of Thompson' s characters, and contributes a number of ideas and strategies that I have incorporated into my own work. In particular, the sound hallucinations heard by the play' s protagonist, Dee, teetering on the edge of breakdown, shape the audience' s perception of her internal world, interacting powerfully both with dialogue and the sounds of performance. Striking parallels exist between the treatment of sound in I Am Yours and the way that voice and ensemble work together in opera. Each character has a distinctive pitch and rhythm to their vocal delivery that defines their persona, heightened by an emotional inflection extending beyond realism towards hysteria.

Complicité' s The Encounter (2015), a one-man show directed and performed by Simon McBurney, reinforced by a small team of sound operators, starts as a demonstration of binaural recording, then transports the audience (via a visit to McBurney' s home where he tries unsuccessfully to get his his small child to go to bed) to the Amazonian rain forest in the 1960s, where an American anthropologist comes face-toface with people who have never before encountered a white man. In The Encounter, the audience members wear headphones, immersing them in the play's sound world as a Heart of Darkness-type narrative unfolds. This piece relies almost completely on diegetic and meta-diegetic sound to envelop its audience and steer their understanding of the narrative; the effect is deeply absorbing, at times shocking and frightening, sometimes funny, but most of all a powerful reminder of the potential of sound in the theatre, providing a model in spoken word theatre of what might be achieved by integrating sound design with music composition in opera.

\section{The Trilobite: Working Methods}


In common with many other composers, I use notation software to compose music. In order to sequence audio, however, I work with Ableton Live. By channeling audio from Sibelius notation software through Ableton Live via ReWire, it is possible to hear audio from Ableton Live and Sibelius simultaneously while having both score and DAW sequences displayed on screen. For field recording, I use a hand-held digital recorder with built-in stereo microphones, supplemented where needed with a compact shotgun microphone for directional recording. Occasionally, I have used my iPhone to record sounds on the spur of the moment, or have sourced sound files online where obtaining them through field recordings has proved impractical.

The advantage of field recording is that it gives rise to a much more vivid creative experience than sourcing audio online. Immersing myself in the sound environment of the characters makes it much easier for me to bring them to life. I have driven to North Devon with Glyn Williams, and walked with him from the beach at Combe Martin to the tops of the Exmoor cliffs, sharing the vista with him of the lost land of Wales across the Bristol Channel. Through sound recording, these journeys become reproducible audio performances, just as Foley artists perform the sounds associated with a film character in post-production, or (as in Nicolas Becker' s case) collect location sound to assemble a sound montage for the same purpose. This practice has helped to give me a more immediate identification with my characters, and enabled me to preserve and develop the memory of walking in their footsteps by replaying the recordings during the composition process.

Recording, audio sequencing/processing and composition are intimately intertwined in my creative process. From the initial rough scenario of The Trilobite, I determined the kinds of sounds that I wanted to use in each scene, and went out on location to Exmoor, Dartmoor and elsewhere to collect the sounds that I needed. Then I worked them together with musical ideas and text to create the scene as a whole. The text itself was prepared in advance as a rough outline of the scenario, then used or discarded as required. The editing process was quite severe, ideas in the text being frequently jettisoned if they were better expressed in sound or music, or abandoned altogether if they failed to live up to their initial promise.

It was important to me that text did not become the dominant means of communication in my operas, as it has become in many contemporary operas. $\frac{39}{\text { Instead, }}$ I wished to find a balance, and a flexible, dynamic relationship between all the elements in my work, choosing the most suitable medium at any given point for the expression of an element in the scenario. In this way, I found I was able to tell the story on several 
levels at once through the words, the actions of characters, the sound design and the music, and to use the relationships between them to convey the overall picture of the narrative and the emotional temperature at any moment. Each scene expresses through music and sound a mood, or affect, as well as having a characteristic underlying tempo or pulse; these tie together the various means of expression, and create a coherent unit. Scenes juxtapose one level of energy or emotional register with another, lending variety to the scenes and creating the overall structure as a series of blocks of action/music following each other in much the same way that a suite of short pieces comes together as a whole.

As slightly chaotic Chionian acousmetres, the sixth formers wield the power of life and death over Glyn. Their voices were created by Florian Saturley, Chelsea Vincent and Alex Robins, three young actors based in Plymouth, during a semi-scripted improvisation session at Plymouth University on 19 October 2018. The journey to Exmoor in the minibus was entirely improvised, complete with toilet breaks, quarrels between the students, and the reaction of Jamie and Ryan, who witness Glyn going over the edge; the initial repeated cries of 'Sir!' and the material for the final hospital scene were scripted. We explored a number of other scenarios during the session, including a scene set in the classroom where Glyn fails to keep control of his class, and although these didn' t make it to the final piece, they provided valuable background material. This working method, of recording improvised and semi-improvised material, proved immensely valuable, as it contributed a freshness and spontaneity to the piece that would have been challenging to achieve in any other way.

The Trilobite is scored for mezzo-soprano (Anna Prowse), tenor (Lars Fischer, who plays Glyn Williams) and baritone (Peter Edge), with an ensemble of clarinet, piano and 'cello augmented by sound cued from a laptop. The necessity of adapting the piece as a oneman show, with video projection and without live instrumental music, transformed both the performance and the rehearsal process. Instead of bringing the cast members together, I had to work with all three separately. I recorded Anna Prowse and Peter Edge' s solo performances on video using green screen, and spliced them together with the Sibelius/Ableton audio into a number of video cues that became Lars' $s$ accompaniment. He and I rehearsed together for a week at Trinity Laban before presenting the piece live on the $17^{\text {th }}$ September at the Cockpit as part of Tête à Tête: The Opera Festival. It was streamed online on the $19^{\text {th }}$ September with an introduction by festival director Bill Bankes-Jones, and followed by a Q \& A session with the cast. 
The (initially unplanned) use of video accentuates the separation, and alienation, between Glyn Williams and the other characters who appear in The Trilobite. The Senior Leadership Team at his school are all too real, if self-caricaturing, as are the love of his life Melanie and her husband Guy the gym teacher. At one remove are the scientists: Glyn has never met them, but their negative response to his letter confirms their reality in his world. The angels, and the judge and clerk of court, lie further off still: they are imaginary, but elicit from him real emotional responses of anger and fear. Finally, the surgeons are glimpsed on the other side of Glyn' s near-death experience, heralding a future as yet unknown - they may be real, or not. As images projected on screen, they all occupy a rectangular thought-bubble above Glyn' s head, thereby physically locating themselves for the audience firmly in his mind. They loom, but they cannot physically coexist with him on stage, an opportunity that might be afforded them in a forthcoming fully live production. Such a production is, however, likely to have accrued attributes from the Covid-19 version as a kind of intermedial sedimentation.

\section{Time and narrative in The Trilobite}

In The Trilobite, I piece together a mosaic of narrative fragments. The playing time of The Trilobite is around 23 minutes, or 11 seconds of Glyn' s time as he falls through the air. The angels and the judge and clerk of court seem to exist outside time. Glyn obsessively rehearses his lecture to the Royal Geographical Society, introducing a circular element to the narrative. It is forever being interrupted, an index of his chronic frustration. The only linear narrative points towards the Exmoor cliffs: once the green light is given by the Senior Leadership Team, Glyn and the students make a beeline towards them. As Glyn goes over the edge, however, we realise that even this narrative is circular, as we find Glyn where we first saw him, falling through the air.

One strand of the narrative runs backwards, shadowing the countdown that runs throughout the piece. We meet Melanie and Guy three times: the first time, Melanie is announcing her forthcoming marriage to Guy; the second time, she is trying to let Glyn down gently about her growing love for Guy. Finally, in the penultimate scene, we witness the moment when Melanie first introduces Guy to Glyn. We hear only the characters' voices, and see their faces on screen: the absence of any other sound or image underlines the devastating emotional impact of this moment, and its timing in the 
piece, just after we see Glyn launch himself over the edge, binds the metaphor of falling inextricably with the actual physical sensation.

\section{Sound and Music: Juxtaposition, Interrelation and Integration}

The Trilobite opens with music and sound in antiphonal opposition, competing to express the mayhem of free fall. A fractured, stuttering 12-note series articulating Glyn's tumbling disorientation alternates with the white noise of rushing wind; succeeding iterations permutate the pitches like bells ringing the changes, while the white noise undergoes heavier compression on each repeat, increasing its overwhelming loudness. Both are used thematically: the 12-note series punctuates the action and pervades Glyn' $s$ solo arias, while the white noise is heard later in the piece as the narrative arc returns to the moment when Glyn is launched off the top of the cliff, drawing a veil over his descent into an abyss of nothingness.

Much of the coherence of the piece is created by interrelating thematic ideas and structural processes between music and sound, often using Chion's 'pivotdimensions' of pitch, rhythm and register. When the angels appear later in the first scene, the airy downward glissandos that accompany them are reinforced by chromatically descending arpeggios in the piano. Later in the scene, these transform into chromatically descending scales, accompanied by a peal of wedding bells that sarcastically remind Glyn of his failure in love; their changing descending sequences hark back to the tumbling permutations of the 12-note series earlier in the scene. In the next scene sea waves boom in D minor, underpinning Glyn's aria and the nihilistic D minor motet of the angels. In scene 4, after his humiliation at the hands of the scientists, the tapping of Glyn's hammer creates pitch patterns which morph into a hesitant piano accompaniment to his hopeless longing for love. And during the ill-fated trip to Exmoor, the windscreen wipers of the minibus, the students' personal stereos and the looped voice of the student (who draws Glyn's ire for finding his trilobite) unite with the instrumental ostinatos in a condemnatory rhythm underpinning the whole beach scene.

During the final scene, music and sound tell simultaneous narratives. Glyn finally gives his lecture in the manner of a TED talk, trilobite fossil in hand, confidently addressing both the real audience in the theatre and his imaginary audience at the Royal 
Geographical Society. Meanwhile the sound of a helicopter, followed by an ambulance, then a heart monitor, relate his journey from the Exmoor cliffs to hospital. As the heart monitor' s pulses give way to a flatlining tone, music and sound rejoin at the same pitch as the angels tell him that he will never give his Royal Geographical Society lecture. This is when the students intervene, showing their power of omnipotence: their voices, as they return in triumph after a second trip to the fossil beds of North Devon, bring Glyn back to life.

\section{Bibliography}

Brown, Ross. "The Dramaturgy of Sound." Keynote Paper at International Sound Design Colloquium, London, Royal National Theatre, 2002. From the author' s archive held at Central School of Speech and Drama.

Casanelles, Sergei. "Mixing as a Hyperorchestration Tool." The Palgrave Handbook of Sound Design and Music in Screen Media: Integrated Soundtracks, edited by Liz Greene and Danijela Kuzelic-Wilson, 57-72.London: Palgrave Macmillan, 2016.

Chion, Michel. Audio-Vision: Sound on Screen. Translated by Claudia Gorbman. New York: Columbia University Press, 2019.

Cook, Nicholas. Analysing Musical Multimedia. Oxford: Oxford University Press, 1998.

Deutsch, Stephen and Larry Sider. "Report: The School of Sound 2015." The New Soundtrack 5, no. 2 (2015): 167-170.

Hardiman, A. "Sound Design for a World Premiere Opera." Lighting and Sound America, May 2007, accessed February 9

2017, http://abcbuzz.com/printmedia/performances/LSA0705Sound\%20Design $\% 20$ for\%20a \%20World\%20Premiere\%200pera.pdf.

Huvenne, Martine. "Intertwining Music and Sound in Film." The Palgrave Handbook of Sound Design and Music in Screen Media: Integrated Soundtracks, edited by Liz Greene 
and Danijela Kuzelic-Wilson, 123-138.London: Palgrave Macmillan, 2016.

Kaye, Deena and LeBrecht, James. Sound and Music for the Theatre (Fourth Edition). Abingdon: Focal Press, 2016.

Kivy, Peter. Music Alone: Philosophical Reflections on the Purely Musical Experience. Ithaca: Cornell University Press, 1990.

Kulezic-Wilson, Danijela. "Musically Conceived Sound Design, Musicalization of Speech and the Breakdown of Film Soundtrack Hierarchy." The Palgrave Handbook of Sound Design and Music in Screen Media: Integrated Soundtracks, edited by Liz Greene and Danijela Kuzelic-Wilson, 429-443. London: Palgrave Macmillan, 2016.

Meyer, Petra. "Sound, Image, Dance, and Space in Intermedial Theatre: Past and Present." In The Oxford Handbook of Sound and Image in Western Art, edited by Yael Kaduri, 236-255. Oxford: Oxford University Press, 2016.

Meyer, Petra. Acoustic Turn. Munich: Fink, 2008.

Morra, Irene. "Outstaring the Sun: Contemporary Opera and the Literary Librettist.” Contemporary Music Review 29, no. 2 (2010): 121-135.

Rebstock, Matthias and David Roesner. Composed Theatre. Bristol and Chicago: Intellect, 2011.

Solomos, Makis. From Music to Sound: The Emergence of Sound in 20th- and 21stCentury Music. London and New York: Routledge, 2020.

Van Leeuwen, Theo. Speech, Music, Sound. Basingstoke: Macmillan, 1999.

Varopoulou, Eleni. "Musikalisierung der Theaterzeichen." Lecture at the first International Summer Academy in Frankfurt am Main, August 1998. In Hans-Thies Lehmann, Postdramatic Theatre, 195. Taylor and Francis, 2006. Kindle.

\section{Media Cited}

Adams, John. Dr Atomic. 2007. Opera. 
Andriessen, Louis. Writing to Vermeer. 1999. Opera.

Anthony Davis Wakonda’'s Dream. 2007. Opera.

Birtwistle, Harrison. The Mask of Orpheus. 1986. Opera.

Complicité The Encounter. 2015. Theatre production.

Jonathan Harvey Wagner Dream. 2013. Opera.

Judith Thompson I Am Yours (Shared Experience / Royal Court production, London, Ambassadors Theatre, 1998). From Ross Brown's archive held at Central School of Speech and Drama.

Olga Neuwirth Lost Highway. 2003. Opera.

Wuthering Heights. Directed by Andrea Arnold. London: Film4, 2011. DVD.

\section{Biography}

Elfyn Jones is a Welsh-speaking composer, opera maker and music educator. He trained at Cardiff University (BMus 1st 1993) and Guildhall School of Music and Drama (MMus 1995), and on attachment with London Sinfonietta (1994/5). Elfyn has taught at Guildhall School of Music and Drama, led creative music projects for Welsh National Opera, BBC National Orchestra of Wales and St David's Hall Cardiff, and was a Core Group Leader for ENO Baylis for ten years. He moved to Devon in 2004 to work as Music Development Leader for Devon Music Service and Composer/Musical Director for a number of theatres in South West England including The Brewhouse Taunton, Theatre Royal Plymouth and Exeter Northcott. He was accompanist for Gareth Malone's BBC TV series Military Wives in 2011. Currently he directs $\underline{\text { Sonopera }}{ }^{\circledR}$ CIC, teaches composition for Junior Trinity, and works freelance as a musician and music educator. Elfyn has just submitted his $\mathrm{PhD}$ project Sound Design for the Opera Composer: Concepts and Methods at Goldsmiths, University of London. 
Commissions include musical theatre (The Firebucket, ENO Baylis 1999), music for dance (Fair and Softly Goes Far, NDCW 2011), music for orchestra (St George, Artist Recording Company 2013), chamber music (String Quartet No 1, Aylwin String Quartet 2008) and a number of plays. His symphony The Journey was premièred by De Havilland Philharmonic in 2011. Opera includes The Nightjar (Tête à Tête commission 1999), The Dead of Night (Opera North commission 2003), Jacko’s Hour (Opera Engine 2009), The Trial of Jean Rhys (Opera Europa 2011 and ROH Exposure 2011-2012), and Nine Stories High (WNO commission 2012). He began his PhD Sound design for the opera composer: concepts and methods at Goldsmiths in 2014, and submitted this summer. It includes three operas with integrated sound design, all shown at Tête à Tête: The Opera Festival. These are: Vicky and Albert(2018)., Her face was of flowers (2019)., and The Trilobite, Or The Fall Of Mr Williams (2020). They will tour together in 2022/3 as The Triptych, produced by Sonopera.

\section{Footnotes}

1.

The notion of music being an autonomous artistic medium is encapsulated in Peter Kivy, Music Alone: Philosophical Reflections on the Purely Musical Experience (Ithaca: Cornell University Press, 1990);

Nicholas Cook, Analysing Musical Multimedia (Oxford: Oxford University Press, 1998), viii. $\triangleq$

2. Ibid., 23.

3. Ibid., 22.

4. Ibid., 23. $\leftrightharpoons$

5. Ibid., 263. $\leftrightarrows$

6. Theo Van Leeuwen, Speech, Music, Sound (Basingstoke: Macmillan, 1999), 92.

7. Makis Solomos, From Music to Sound: The Emergence of Sound in 20th- and 21stCentury Music (London and New York: Routledge, 2020), 13. $\_$

8. Ibid., 113. $匚$

9. Ibid., $114 . \leftrightharpoons$ 
10. Ibid., 115.

11. Ibid., 121. $\bullet$

12. Ibid., 132. $\doteq$

13. Petra Meyer, Acoustic Turn (Munich: Fink, 2008).

14. Petra Meyer, "Sound, Image, Dance, and Space in Intermedial Theatre: Past and Present," in The Oxford Handbook of Sound and Image in Western Art, ed. Yael Kaduri (Oxford: Oxford University Press, 2016), 3. $\Perp$

15. Ibid., $6 . \pm$

16. Ibid., $7 . \triangleq$

17. Eleni Varopoulou, quoted in Hans-Thies Lehmann, Postdramatic Theatre (London: Taylor and Francis, 2006), 195, Kindle. $\doteq$

18. Ibid., $91 . \leftrightarrows$

19. Ibid., $92 . \longleftarrow$

20.

Ross Brown, “The Dramaturgy of Sound," Keynote Paper at International Sound Design Colloquium, London, Royal National Theatre, 2002. From the author's archive held at Central School of Speech and Drama;

Deena Kaye and James LeBrecht, Sound and Music for the Theatre (Fourth Edition) (Abingdon: Focal Press, 2016), x. $\leftrightarrows$ 21. Matthias Rebstock and David Roesner, Composed Theatre (Bristol and Chicago: Intellect, 2011), $8 . \subseteq$

22. Ibid., 123. \pm

23. Ibid., $127 . \pm$

24. Ibid., 124. $\subseteq$

25. Ibid. $\doteq$

26. Michel Chion, Audio-Vision: Sound on Screen, trans. Claudia Gorbman (New York: Columbia University Press, 2019), 24. 
27. Ibid., $5 . \triangleq$

28. Ibid., $25-27 \subseteq$

29. Ibid., 34.

30. Ibid., 125-127.

31. Ibid., $151-153 \subseteq$

32. Stephen Deutsch and Larry Sider, "Report: The School of Sound 2015," The New Soundtrack 5, no. 2 (2015): 168.

33. Danijela Kuzelic-Wilson, "Musically Conceived Sound Design, Musicalization of Speech and the Breakdown of Film Soundtrack Hierarchy," The Palgrave Handbook of Sound Design and Music in Screen Media: Integrated Soundtracks, ed. Liz Greene and Danijela Kuzelic-Wilson (London: Palgrave Macmillan, 2016), 431.

34. Martine Huvenne, "Intertwining Music and Sound in Film," The Palgrave Handbook of Sound Design and Music in Screen Media: Integrated Soundtracks, ed. Liz Greene and Danijela Kuzelic-Wilson (London: Palgrave Macmillan, 2016), 123.

35. Sergei Casanelles, "Mixing as a Hyperorchestration Tool," The Palgrave Handbook of Sound Design and Music in Screen Media: Integrated Soundtracks, ed. Liz Greene and Danijela Kuzelic-Wilson (London: Palgrave Macmillan, 2016), 58.

36. Ibid., $70 . \longleftarrow$

37. Anthony Davis, personal correspondence, 18 December 2015.

38. Earl Howard quoted in A Hardiman, "Sound Design for a World Premiere Opera," Lighting and Sound America, May 2007, accessed February 9 2017, http://abcbuzz.com/printmedia/performances/LSA0705Sound\%20Design\%20for\%2 0a\%20World\%20Premiere\%20Opera.pdf.

39. See Irene Morra, "Outstaring the Sun: Contemporary Opera and the Literary Librettist," Contemporary Music Review 29, no. 2 (2010): 121-135. 